\title{
As Humanidades como utopia
}

The Humanities as Utopia

Les Humanités comme utopie

\section{António Sousa Ribeiro}

\section{CpenEdition}

\section{Journals}

Edição electrónica

URL: http://journals.openedition.org/rccs/1280

DOI: $10.4000 /$ rccs. 1280

ISSN: 2182-7435

\section{Editora}

Centro de Estudos Sociais da Universidade de Coimbra

Edição impressa

Data de publição: 1 Outubro 2002

Paginação: 199-207

ISSN: 0254-1106

\section{Refêrencia eletrónica}

António Sousa Ribeiro, « As Humanidades como utopia », Revista Crítica de Ciências Sociais [Online], 63 | 2002, colocado online no dia 01 outubro 2012, criado a 04 maio 2019. URL : http:// journals.openedition.org/rccs/1280; DOI : 10.4000/rccs. 1280 


\section{ANTÓNIO SOUSA RIBEIRO}

Faculdade de Letras da Universidade de Coimbra e Centro de Estudos Sociais

\section{As Humanidades como utopia}

Equacionam-se alguns aspectos da (auto)definição das Humanidades em tempo de reconstrução, defendendo-se o potencial utópico da perspectiva por elas representada num contexto de redefinição global dos saberes.

É bem provável que o título que escolhi soe aos ouvidos de muitos, se não como uma espécie de provocação, em todo o caso como o anúncio de mais uma tentativa, de antemão condenada ao fracasso, de defender uma causa aparentemente há muito perdida. De facto, é verdade que os dois termos do meu título partem de conceitos que têm estado fortemente sob suspeita. Por um lado, a ideia das Humanidades surge como dificilmente separável de um conceito enfático de cultura e de uma noção vincada de hierarquia cultural, estreitamente associada a uma visão canónica do campo das artes - e tudo isto está posto radicalmente em questão num contexto de diluição de fronteiras como o actual em que o alargamento ilimitado do campo da cultura vai de par com a crescente irrelevância da dimensão estética e com uma indiferença de princípio perante a noção de valor. Por outro lado, o conceito de utopia não tem estado propriamente na moda, num contexto em que se tornou manifestamente difícil pensar um futuro que seja mais do que a repetição do presente.

Ao falar das Humanidades como utopia estou mais a formular um problema do que a afirmar uma solução. Mas, se de bom grado aceito uma leitura do meu título no modo interrogativo, não deixo de partir do firme pressuposto de que, se reconhecemos o regresso do futuro como componente fundamental da reconstrução de uma teoria crítica, faremos bem em reconhecer por igual que esse regresso e esta reconstrução se jogam também, e de modo decisivo, no campo das Humanidades. Afirmar isto corresponde a afirmar que as Humanidades têm futuro e obriga-me, naturalmente, a particularizar qual é o futuro das Humanidades. É assim que o contexto desta mesa redonda me oferece uma oportunidade bem-vinda de tecer 
algumas considerações, mesmo que sumárias, sobre o papel das Humanidades no âmbito da redefinição dos saberes em tempo de globalização. Fá-lo-ei do lado das Humanidades, puxando assim, inevitavelmente, a brasa à minha sardinha. Mas fá-lo-ei, espero, igualmente para além das duas - ou das três - culturas (Lepenies, 1985).

Numa das suas conversas com Eckermann, em 15 de Outubro de 1825, lamentava Goethe que o progresso das ciências fosse alargando, é certo, o âmbito do conhecimento exacto das coisas, mas, ao mesmo tempo, muitas das verdades assim produzidas de pouco servissem, isto é, não apresentassem relevância para o que lhe parecia realmente importante do ponto de vista do ser humano (Eckermann, 1955: 150). Reconhece-se aqui, evidentemente, a unilateralidade da perspectiva humanista; mas reconhece-se também a incomodidade perante a progressiva ocupação do campo do saber pela lógica da previsibilidade determinista. Por outras palavras, o que, aos olhos de Goethe, ia ficando cada vez mais por responder era o problema central do Iluminismo, o problema da relação entre a racionalidade objectiva do conhecimento e a moralidade subjectiva da acção.

É sabido como o século XIX assistiu ao definitivo triunfo das chamadas "ciências da natureza" e ao estabelecimento de uma sistemática das ciências em que a ideia da unidade do saber cedeu o passo à pulverização em disciplinas de acordo com modelos em que, nomeadamente, as perspectivas literária, histórica ou antropológica deixaram de ter lugar ou foram sendo acantonadas em domínios de "especialidade". Neste contexto, as Humanidades, redefinindo-se como "Ciências do Espírito", aceitaram ser remetidas para um papel, no fundo, residual, de acordo com uma peculiar divisão dicotómica do trabalho que lhes deixava por objecto o cada vez menos que ia ainda ficando de fora de um conceito cada vez mais abrangente de natureza.

Assim reduzidas a uma posição defensiva, as Humanidades não deixaram de procurar novas fontes de legitimação. Encontraram-nas, por um lado, através de uma deriva cientista, com que quiseram travar, num campo que não era o seu, uma luta antecipadamente perdida. E encontraram-nas, por outro lado, através de uma marcada deriva nacionalista: na forma, por exemplo, da história nacional ou das filologias nacionais, elas fizeram sua a tarefa de transformar uma ideia canónica de tradição cultural em instrumento de mitologias nacionais directamente apropriáveis pelas várias burguesias que, melhor ou pior, iam redesenhando os diferentes estados à medida dos seus interesses. Assim, a tradição humanista de uma cultura letrada foi posta ao serviço de um projecto educativo aparentemente consensual, 
coincidente com a ideia de nação. Neste processo, a retórica universalista do humanismo iluminista associou-se a uma noção enfática de cultura mediada pela forma do Estado nacional e achou-se posta ao serviço das ficções do centro com que esse Estado cimentava ideologicamente a legitimidade do seu projecto. O cosmopolitismo iluminista, mesmo se de uma perspectiva em que hoje facilmente reconhecemos o viés eurocêntrico, cultivara uma abertura para o Outro que agora desaparece do horizonte cultural ou é reconfigurada sob o signo da dominação, na forma, por exemplo, da lógica epistemicida das "ciências coloniais" - sem dúvida, um dos aspectos daquilo que Boaventura de Sousa Santos tem vindo a analisar como a sobreposição do eixo da regulação ao eixo da emancipação no processo da modernidade (Santos, 2000). Submetidas à perspectiva localista do Estado nacional, as Humanidades foram-se traduzindo num saber simplesmente instrumental - o culto de valores aparentemente desinteressados e de uma ficção de autonomia revelava-se afinal como condição de eficácia na subordinação a um conceito de cultura assente na lógica da regulação.

Talvez a acusação mais violenta lançada contra uma ideia de cultura como a tradicionalmente associada ao conceito de Humanidades seja a contida na reiterada reflexão de Adorno sobre o modo como Auschwitz põe radicalmente em causa toda a definição de cultura como promessa de emancipação. Desde Auschwitz, segundo o teórico de Frankfurt, todo o simples postulado da cultura como lugar de sentido ou como o outro da lógica cega da modernidade se nega a si próprio e se revela como parte da barbárie de que supostamente procura demarcar-se. E, no entanto, não pode deixar de observar-se que a demonstração da inanidade de uma tradição cultural humanista vai de par, na reflexão de Adorno, com o apego a uma ideia de cultura: "Quem defende a manutenção dessa cultura radicalmente culpada e reles torna-se cúmplice, enquanto quem diz não à cultura está a favorecer directamente a barbárie que a cultura revelou ser", lê-se, por exemplo, num passo central da Dialéctica negativa (Adorno, 1966: 360).

É no seio deste paradoxo de uma simultânea crítica e defesa da cultura que a ideia das Humanidades tem de ser reconstruída nos nossos dias. Aceitar a inevitabilidade desse paradoxo nada tem de paralisante, pelo contrário: ele permite-nos escapar à definição residual de Humanidades, assente na dicotomia entre natureza e espírito, a que há pouco me referia e permite, assim, ir para além da síndrome das "duas culturas" enquanto expressão do abismo aparentemente intransponível entre o universo de um sujeito pretensamente íntegro e idêntico, objecto do conhecimento das Humanidades, e os processos da natureza, objecto das ciências - ou das tecnociências, como, com boas razões, prefere dizer João Arriscado Nunes, que, num 
artigo recente, intitulado justamente "Para além das duas culturas", dedicou a este problema algumas páginas sobremaneira estimulantes (Nunes, 1998/1999).

Significa isto que as Humanidades só têm futuro a partir do momento em que se mostram capazes de incorporar na sua autodefinição a tarefa da reconstrução da própria ideia de cultura, indo assim, aliás, ao encontro do melhor da tradição auto-reflexiva do seu próprio campo. É verdade que essa reconstrução, como é patente, não surge apenas a partir de dentro, mas constitui a resposta a um conjunto de transformações sociais. $\mathrm{O}$ mais tardar a partir de finais dos anos sessenta, a noção de crise tornou-se omnipresente, num processo estreitamente associado à crise das universidades e ao efeito de abertura suscitado pelo impacto violento dos movimentos estudantis sobre práticas institucionais e tradições científicas até aí fechadas sobre si próprias. Concomitantemente, ia-se completando a erosão da posição de privilégio de uma cultura literária, definitivamente posta em causa pela revolução dos media e pela imparável ascensão de uma cultura de massas, associadas ao conjunto complexo de mutações sociais a que desde há algum tempo nos habituamos a chamar globalização. Assim, tanto a função de agentes de uma cultura nacional como a definição do campo das Humanidades de acordo com uma lógica de compensação dos défices da modernidade se tornaram definitivamente insustentáveis. Tornou-se, pois, mais fácil recusar uma situação epistemológica em que a autonomia do campo da Humanidades mais não fazia afinal do que confirmar a rigidez das dicotomias da modernidade que supostamente punha em causa.

Uma consequência deste processo de redefinição das Humanidades é o abandono do acantonamento na racionalidade estético-expressiva como fonte última de legitimação. Assim, diga-se de passagem, essa redefinição vai ao encontro do desiderato formulado por Immanuel Wallerstein, quando teoriza a necessidade de "despensar" (unthink) "a mais persistente (e enganadora) herança das ciências sociais do século XIX - a divisão da análise social em três áreas, três lógicas, três 'níveis' - o económico, o político e o sócio-cultural" (Wallerstein, 1991: 4). Por outras palavras, cumpre às Humanidades pensar transversalmente os domínios autonomizados pela modernidade, em vez de se resignar a essa autonomização. Ou, dito ainda de outro modo, já não se trata de tomar como objecto a cultura, mas sim a forma cultural do mundo (Frühwald et al., 1991: 41).

O que isto possa querer dizer é algo que se tornou igualmente mais fácil de reconhecer no contexto actual. É evidente para todos, como, entre outros, tem vindo a ser insistentemente recordado por Michel Serres, que o deus da nossa época não é já Prometeu - o deus da transformação pelo fogo, da 
revolução industrial - mas Hermes - o deus da mensagem e da comunicação. O que acarreta, nomeadamente, uma consequência que temos bem diante dos nossos olhos, embora nem sempre sejamos capazes de a reconhecer: no mundo de hoje, a linguagem e a cultura tornaram-se em decisivos meios de produção. Por outras palavras, na época de Hermes, aquilo que era o tradicional objecto das Humanidades - a começar pela linguagem adquire uma nova centralidade. Mas adquire-a em condições marcadas pela tendencial redução da linguagem a informação e, concomitantemente, pela incrível aceleração global do tempo da informação, a qual, como defende Scott Lash (Lash, 1999), vem pôr em causa a ideia mesma de crítica e só deixa espaço para uma crítica melancólica, impelida, tal como o Angelus Novus de Benjamin, para um futuro que não deseja, ao mesmo tempo que mantém o olhar pousado num passado catastrófico que não poderá nunca redimir. E é entre esta melancolia e um renovado sentido de contemporaneidade que se vê hoje colocada a ideia das Humanidades.

Lembrava Boaventura de Sousa Santos no seu absolutamente seminal Discurso sobre as ciências que o que há de futuro nas Humanidades "é terem resistido à separação sujeito/objecto e terem preferido a compreensão do mundo à manipulação do mundo" (Santos, 1987: 44). Analogamente, os autores de um decisivo balanço crítico sobre As Humanidades hoje publicado na Alemanha em 1991 - entre esses autores estão nomes de referência como Hans Robert Jauss ou Reinhart Koselleck - apontam como eixo central do futuro das Humanidades a assunção da tarefa da "antropologização do saber” (Frühwald et al., 1991:51). Só assim elas serão capazes de produzir um "saber orientador" (Orientierungswissen), feito de perguntas e respostas, capaz de fundamentar uma acção esclarecida - um saber definido por oposição àquele saber simplesmente instrumental (Verfügungswissen), "incapaz de conseguir a conjunção entre os que sabem e os que agem" (ibid.: 68).

O desiderato da antropologização do saber, como é bom de ver, não é senão outra forma de exprimir a resistência à separação sujeito/objecto aludida por Boaventura de Sousa Santos. O problema, naturalmente, é como levar a cabo esse desiderato na era da informação, em que, aparentemente, a dimensão antropológica está condenada a diluir-se por inteiro na rede global. Talvez valha a pena lembrar aqui a oposição entre os conceitos de não-lugar e de lugar antropológico, tal como definidos por Marc Augé (1994). Os lugares antropológicos definem contextos de sentido que desempenham uma função estruturante na formação da memória e na produção do saber. Trata-se de lugares que permitem a afirmação de uma identidade susceptível de servir de base estável a uma relação com o outro e que evi- 
denciam uma dimensão histórica constante. Por contraste, o não-lugar caracteriza-se pela figura do excesso: excesso de acontecimentos, uma experiência do espaço marcada pela velocidade e pela fugacidade, e, finalmente, uma multiplicação infinita dos pontos de referência. Os não-lugares são lugares solitários, já que, neles, todo o encontro é por definição fugaz, um simples acidente casual no percurso errático do novo flâneur electrónico.

Dito de outro modo: os processos de globalização, tal como se traduzem, particularmente, na revolução digital, confrontam as Humanidades com lógicas radicalmente descontextualizantes. Ao fazê-lo, obrigam-nas a repensar a sua posição de um modo que corresponde, no fundo, a recuperar vectores essenciais da tradição do paradigma humanista. Diferentemente da concepção moderna de racionalidade, que representa um "ideal descontextualizado", esse paradigma, como lembra Stephen Toulmin (1990), insistia em que o pensamento e a acção não deviam ser apenas racionais, mas também razoáveis, tolerando a diversidade social, cultural e intelectual. Esta "razoabilidade" traduzia, no fundo, uma atitude profundamente contextualista, atenta mais à contingência do que às regularidades deterministas, mais ao particular e ao concreto do que à generalização abstracta.

É, sem dúvida, numa tal exigência contextualizante que reside um dos aspectos decisivos do impacto dos cultural studies sobre o conjunto dos saberes contemporâneos. É essa exigência que permite não perder de vista tudo aquilo que resiste à lógica da indiferenciação - a começar pelo sofrimento concreto dos seres humanos. No entanto, e concedendo plenamente a importância do projecto dos cultural studies, a reconstrução das Humanidades de que tenho vindo a falar de modo nenhum se esgota nesse projecto, sobretudo lá onde ele tende a confinar-se num fenomenologismo descritivista que arrasta consigo a perda da dimensão crítica. Não se trata, de facto, de levar as Humanidades a renunciarem a uma vocação interpretativa, mas sim de assumir essa vocação transformando-a, ao mesmo tempo, num sentido interpelativo. E é assim que categorias como as de valor, de diferença, de distinção ou mesmo - borribile dictu - de hierarquia (Jay, 1984/ 1985) continuam a ter um papel a desempenhar. Noutras palavras, e retomando o que escrevi noutro lugar: "só um 'pós-modernismo de reacção' se satisfaz numa ilusória diluição das fronteiras. Um pensamento crítico, pelo contrário, é, por definição, um pensamento fronteiriço, exerce-se, não para além das fronteiras, mas na fronteira." (Ribeiro e Ramalho, 1998/1999: 76).

Sabemos que a linguagem - e, por extensão, a cultura - não é apenas o que une, mas também o que separa. Mas sabemos igualmente - esta é uma percepção elementar de qualquer teoria da fronteira - que nenhuma fronteira é estática ou estanque, mas é sempre dinâmica e porosa. É como razão 
fronteiriça, preocupada com os espaços de articulação e com as condições de existência desses espaços, que as Humanidades podem configurar-se como utopia, assumindo-se como metadiscurso a um tempo integrador e interrogativo. Utopia, desde logo, de um tempo-outro, já que o seu tempo não se confunde com o tempo da informação. Mas utopia também enquanto recusa da lógica rasurante das formas hegemónicas de globalização e enquanto modelo de integração da diferença capaz a um tempo de preservar a alteridade desta e de instaurar condições igualitárias de diálogo, no sentido de um conceito de tradução entendido, de acordo com Benjamin, não como um modo de assimilação, mas sim como o pôr em relação do diverso.

A exigência contextualista inerente ao desiderato da "antropologização do saber" não se confunde com a tradicional busca das raízes. E não se confunde, desde logo, porque, ao basear-se num conceito de contingência, ela põe em causa a própria ideia de raiz. A noção de contingência leva-me à breve conclusão deste meu ensaio e - para que não se diga que me deixei ficar apenas do lado de cá das duas culturas - oferece-me a oportunidade de dizer duas palavras sobre as ciências exactas. De facto, o desiderato de pôr a ciência em cultura reclamado por Bruno Latour tem muito que ver, entre outros aspectos, com a incorporação do conceito de contingência na perspectiva epistemológica dessas ciências. Limitar-me-ei a exemplificar com as ciências da vida e, em particular, com as últimas reformulações das teorias evolucionistas. Estas têm vindo a chamar a atenção para o facto de que não é possível conceber a evolução como um processo linear de causa e efeito, mas antes como o resultado de situações contingentes que bloquearam vias evolutivas aparentemente promissoras ou, pelo contrário, ofereceram oportunidades a vias improváveis. O biólogo, como escreve Isabelle Stengers, vê-se colocado perante uma situação de nebulosa complexidade e é levado a responder através da formulação de narrativas múltiplas capazes de fazer justiça à diversidade das hipóteses que pode construir (apud Ceruti, 1999: 9). É assim que, como defende Stephen Jay Gould, "muitas áreas da natureza [...] têm de ser estudadas com os instrumentos do historiador", já que, como continua o autor, o que acontece na natureza acontece, como é óbvio, de acordo com as leis gerais da matéria, mas acontece também no âmbito de um conjunto de circunstâncias contingentes (Gould, 1989: 284). Isto é, a reconstrução da memória do Universo lança mão de instrumentos que fazem parte do arsenal das Humanidades, a começar pelo instrumento da reconstrução narrativa. Esta permite, não apenas exprimir o que foi, mas também o que poderia ter sido, as possibilidades não realizadas. Assim, ficcionar mundos possíveis revela-se, não apenas como parte do discurso 
das Humanidades, mas também do discurso das ciências exactas. O que significa que, tal como as Humanidades, as ciências exactas são levadas a lidar também com realidades concebidas como textos, e não apenas como conjuntos de dados. E não é por acaso que a metáfora do texto continua a ser das mais estimulantes - justamente porque a materialidade do texto traduz um conjunto de opções tomadas entre várias alternativas possíveis e depende de um conjunto de decisões contingentes que não é possível rasurar por inteiro, mas que, pelo contrário, se mantêm sempre latentes na própria estrutura textual. Esta latência é um dos modos de pôr em questão a aparente opacidade do real, mantendo presente a tensão entre o que é ou foi e o que não é ou não foi, mas poderia ter sido. E o espanto perante o que poderia ter sido, o desassossego que permite ver abismos onde aparentemente não há senão lugares comuns, são, evidentemente, fermento de utopia - e são um dos pontos em que é possível um encontro entre ciências exactas e Humanidades susceptível de perturbar decisivamente as evidências disciplinares de cada um dos campos.

Talvez a aquisição mais duradoura do pensamento pós-moderno tenha sido a defesa de uma epistemologia prudente, capaz de moderar as excessivas ambições que marcaram as narrativas matriciais da modernidade. De bom grado aceito essa prudência como nota final, se ela significa, no contexto da minha argumentação, que nenhum saber, por si só, emancipa. Mas seja-me permitido assumir do mesmo passo, plenamente, as consequências da fórmula que escolhi como título. É que, se não será difícil pormo-nos de acordo sobre a centralidade do conceito de cidadania para a temática do nosso colóquio, talvez possamos também concordar em que, por maioria de razão na era da informação global, a cidadania será uma cidadania culta, ou não será. E assim a reconstrução das Humanidades de que falei e que, inevitavelmente, terá de levar-nos "para além das duas culturas" se revela não apenas como necessidade epistemológica, mas também como urgência ética e política.

\section{Referências Bibliográficas}

Augé, Marc (1994), Não-lugares. Introdução a uma antropologia da sobremodernidade. Lisboa: Bertrand.

Adorno, Theodor W. (1966), Negative Dialektik. Frankfurt am Main: Suhrkamp.

Ceruti, Mauro (1999), «Narrative Elements. A New Common Feature between the Sciences of Nature and the Sciences of Societies», Review, 22(1), 1-15.

Frühwald, Wolfgang et al. (1991), Geisteswissenschaften heute. Eine Denkschrift. Frankfurt am Main: Suhrkamp. 
Eckermann, Johann Peter (1955), Gespräche mit Goethe in den letzten Jabren seines Lebens. Frankfurt am Main: Insel.

Gould, Stephen Jay (1989), Wonderful Life. The Burgess Shale and the Nature of History. New York: W. W. Norton.

Jay, Martin (1984/1985), «Hierarchy and the Humanities: The Radical Implications of a Conservative Idea», Telos, 62, 131-144.

Lash, Scott (1999), «Crítica da informação», Revista Crítica de Ciências Sociais, 54, 13-30. Lepenies, Wolf (1985), Die drei Kulturen. Soziologie zwischen Literatur und Wissenschaft. München: Hanser.

Nunes, João Arriscado (1998/1999), «Para além das 'duas culturas': Tecnociências, tecnoculturas e teoria crítica», Revista Crítica de Ciências Sociais, 52/53, 15-60.

Ribeiro, António Sousa; Ramalho, Maria Irene (1998/1999), «Dos estudos literários aos estudos culturais?», Revista Crítica de Ciências Sociais, 52/53, 61-83.

Santos, Boaventura de Sousa (1987), Um discurso sobre as ciências. Porto: Afrontamento.

Santos, Boaventura de Sousa (2000), Crítica da razão indolente. Contra o desperdício da experiência. Porto: Afrontamento.

Toulmin, Stephen (1992), Cosmopolis, the Hidden Agenda of Modernity. Chicago: The University of Chicago Press.

Wallerstein, Immanuel (1991), Unthinking Social Science: The Limits of 19th Century Paradigms. Oxford: Polity Press. 